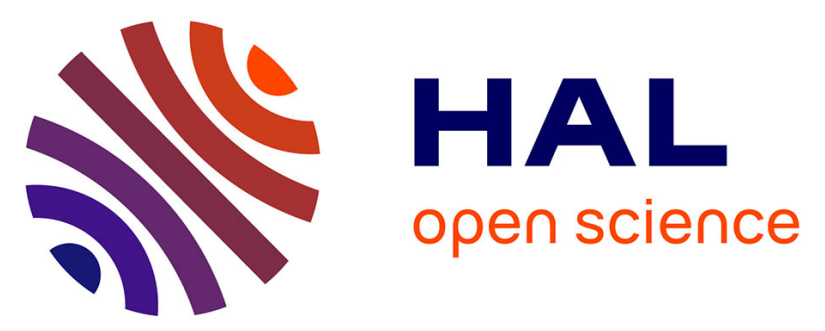

\title{
A Novel Homozygous TBC 1 D 24 Mutation Causing Multifocal Myoclonus With Cerebellar Involvement
}

Diane Doummar, Cyril Mignot, Emmanuelle Apartis, Laurent Villard, Diana Rodriguez, Sandra Chantot-Bastauraud, Lydie Burglen

\section{- To cite this version:}

Diane Doummar, Cyril Mignot, Emmanuelle Apartis, Laurent Villard, Diana Rodriguez, et al.. A Novel Homozygous TBC 1 D 24 Mutation Causing Multifocal Myoclonus With Cerebellar Involvement. Movement Disorders, 2015, 30 (10), pp.1431-1432. 10.1002/mds.26303 . hal-01664305

\section{HAL Id: hal-01664305 https://hal-amu.archives-ouvertes.fr/hal-01664305}

Submitted on 19 Dec 2017

HAL is a multi-disciplinary open access archive for the deposit and dissemination of scientific research documents, whether they are published or not. The documents may come from teaching and research institutions in France or abroad, or from public or private research centers.
L'archive ouverte pluridisciplinaire HAL, est destinée au dépôt et à la diffusion de documents scientifiques de niveau recherche, publiés ou non, émanant des établissements d'enseignement et de recherche français ou étrangers, des laboratoires publics ou privés. 


\section{A Novel Homozygous TBC1D24 Mutation Causing Multifocal Myoclonus With Cerebellar Involvement}

The phenotypic spectrum associated with recessive TBC1D24 mutations comprises focal epilepsy with cognitive impairment, ${ }^{1,2}$ familial infantile myoclonic epilepsy without intellectual impairment, ${ }^{3}$ progressive encephalopathy with myoclonus and dystonia, ${ }^{4}$ progressive myoclonus epilepsy with ataxia, ${ }^{5}$ malignant migrating partial seizures of infancy, ${ }^{6}$ and DOORS syndrome. ${ }^{7}$ Here, we report on the case of a child with cortical myoclonus, cerebellar ataxia, and a novel TBC1D24 mutation.

\section{Case Report}

A 7-month-old boy born to a consanguineous Turkish couple had an acute episode of continuous myoclonus of the right hand lasting a few hours and mimicking epilepsia partialis continua. Interictal clinical evaluation, EEG, and MRI were normal. The boy, who is currently 8 years old, subsequently had attacks of myoclonus occurring once or twice a month, sometimes triggered by fever or fatigue. Myoclonic jerks alternatively affected the eyelids, either the right or left limbs, and sometimes the four extremities or the trunk. They lasted from several hours to up to 2 weeks, mostly disappearing during sleep, with consciousness preserved throughout Video 1,2. At 2 years of age, he had an episode of gait ataxia lasting several days and subsequently developed mild cerebellar syndrome. Mild intellectual disability became obvious after 5 years of age (Wechsler Preschool and Primary Scale of Intelligence at 6 years: verbal IQ: 55; performance IQ: 68 ; he was illiterate at 8 years old). The child did not respond to a number of antiepileptics, but topiramate gave a partial benefit video 3 .

Although interictal EEGs showed isolated spikes or bursts of spikes over bifrontal regions, paroxysmal anomalies were not found on ictal traces. However, video recordings with surface polymyography combined with accelerometry and EEG jerk-locked-back-averaging were, taken together, highly suggestive of the cortical origin of myoclonus (Fig. 1A-C).

Cerebral MRI at 3 and 7 years of age showed progressive hemispheric (but not vermian) cerebellar atrophy with hypersignal of the cerebellar cortex and white matter on T2 and fluid-attenuated inversion recovery sequences (Fig. 1D,E). Single-nucleotide polymorphism analyses performed with the Human CytoSNP-12 kit (Illumina, San Diego, CA) in the patient and his healthy brother identified seven regions of loss of heterozygosity $(\mathrm{LOH} ;>2 \mathrm{Mb})$ present only in the patient. Sequencing of the TBC1D24 gene included in one $\mathrm{LOH}$ region revealed a homozygous c. $809 \mathrm{G}>\mathrm{A}$ (p.Arg270His) mutation, present in a heterozygous state in his parents. This mutation is not reported in the homozygous state in public databases. In the ExAC Database, it is reported in two heterozygous carriers (allele frequency $1.6 \mathrm{E}^{-5}$ ) and is predicted deleterious by Mutation Taster, polyphen-2 (score 0.992), and UMD predictor (Supporting Information).

Recessive mutations in TBC1D24 are associated with epilepsy with ${ }^{3-5,7}$ or without ${ }^{1,2,6,7}$ myoclonus. Long-lasting myoclonus attacks were previously reported in two pedigrees with epilepsy and either normal cognition ${ }^{4}$ or severe encephalopathy. ${ }^{1}$ We report, for the first time, a patient with infantileonset attacks of multifocal myoclonus that, despite their cortical origin, were not associated with other seizure types until 8 years of age. Cerebellar atrophy with hypersignal of the cerebellar cortex is a remarkable feature reported by two previous studies. ${ }^{2,7}$ Brain imaging in other patients showed atrophy of cerebral hemispheres with ${ }^{1}$ or without ${ }^{6}$ cerebellar involvement. Our report confirms that TBC1D24 is responsible for cortical myoclonus and ataxia with cerebellar involvement.

Diane Doummar, MD, ${ }^{1,2,3 *}$ Cyril Mignot, MD, PhD, ${ }^{4}$ Emmanuelle Apartis, $\mathrm{MD}, \mathrm{PhD},{ }^{5,6,7}$, Laurent Villard, $\mathrm{MD},{ }^{8}$ Diana Rodriguez, MD, $\mathrm{PhD}, 1,2,3,7,9$

Sandra Chantot-Bastaraud, MD, ${ }^{10}$ and Lydie Burglen, $\mathrm{MD}, \mathrm{PhD}^{3,9,10}$

${ }^{1}$ AP-HP, Service de Neuropédiatrie, Hôpital Trousseau, Paris, France

${ }^{2}$ Centre de Référence Neurogénétique de l'Enfant à l'adulte, Hôpital Trousseau, Paris, France

${ }^{3}$ Centre de Référence Malformations et Maladies Congénitales du Cervelet, Hôpital Trousseau, Paris, France

${ }^{4}$ AP-HP, Département de Génétique, Groupe Hospitalier

Pitié-Salpêtrière, and Centre de Référence déficiences intellectuelles de causes rares, Paris, France 

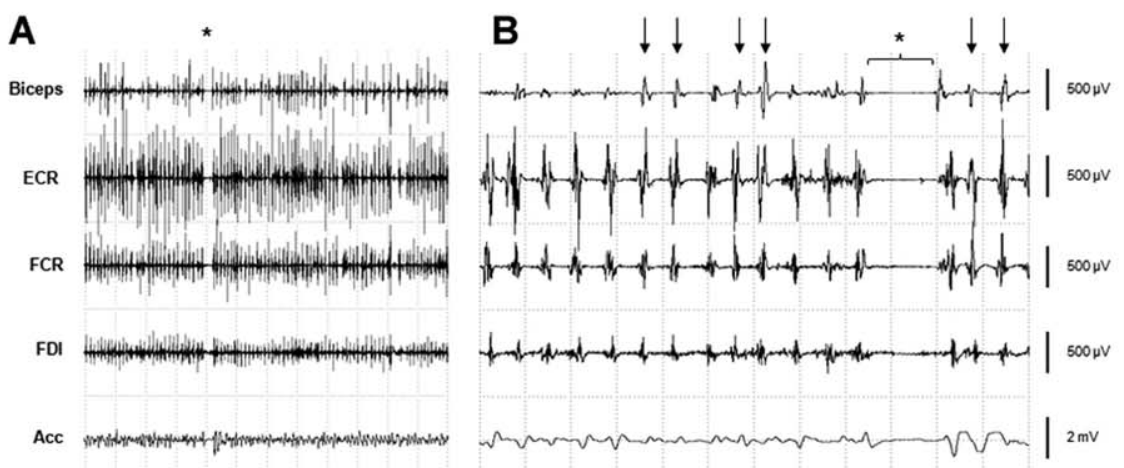

$1 \mathrm{~s}$

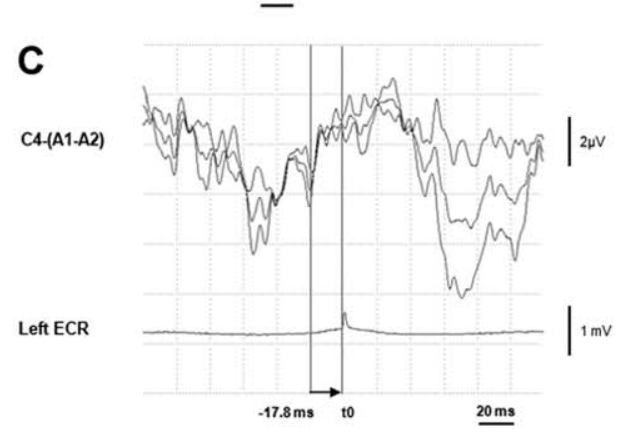

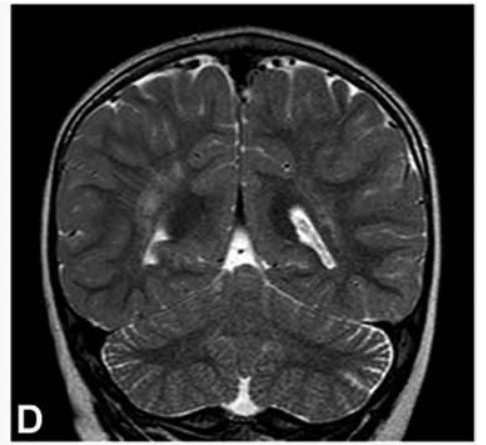

$\underline{200 \mathrm{~ms}}$

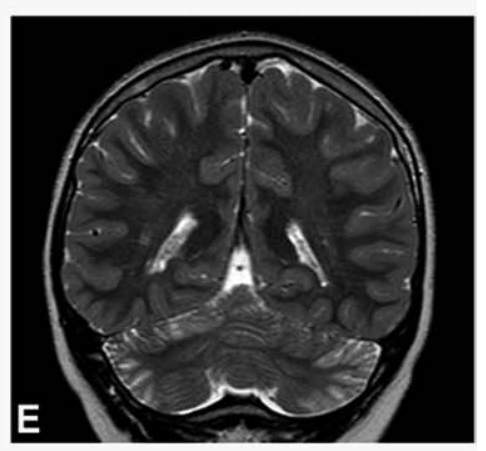

FIG. 1. Neurophysiological exam of the boy at 3 years of age, performed during a myoclonic attack involving the left upper limb: Polymyographic recording ( $\mathrm{A}$ and $\mathrm{B})$ shows profuse continuous positive rhythmic (8-Hz) myoclonus composed of short duration (range, $40-48$ ms) repetitive bursts (arrows), which were synchronous in all the recorded muscles. Negative myoclonus (duration, 270 ms) also occurred intermittently (asterisks), inducing transient loss of tonus. EEG jerk-locked-back-averaging (C) shows a 3- $\mu \mathrm{V}$ transient over the right rolandic central (C4) area preceding myoclonus by $17.8 \mathrm{~ms}$, which, taken together with polymyography, highly suggests the cortical origin of the myoclonus (averaging of 3 consecutive series of 100 positive jerks). Comparison of T2-weighted MRls of the patient's brain at 3 (D) and 7 (E) years of age demonstrates progressive atrophy and cortical hypersignal of the cerebellar hemispheres. A1-A2, ear-linked reference; ECR, extensor carpi radialis; FCR, flexor carpi radialis; Acc, accelerometer.

${ }^{5}$ AP-HP, Unité de Neurophysiologie, Hôpital Saint-Antoine, Paris, France

${ }^{6}$ ICM INSERM, UMRS 975, et CNRS 7225-CRICM, Hôpital Pitié-Salpêtrière, Paris, France

${ }^{7}$ Université Pierre et Marie Curie-Paris-6, Paris, France

${ }^{8}$ Aix-Marseille Université, Inserm, GMGF, UMR_S910, Marseille, France

${ }^{9}$ Inserm U1141, Paris, France

${ }^{10}$ AP-HP, Service de Génétique et d'Embryologie Médicale, Hôpital Armand Trousseau, Paris, France

Acknowledgments: The authors thank the family for participating in this study, and Drs. E. Lopez Hernandez and M. Milh for helpful discussions.

\section{References}

1. Corbett MA, Bahlo M, Jolly L, et al. A focal epilepsy and intellectual disability syndrome is due to a mutation in TBC1D24. Am J Hum Genet 2010;87:371-375.

2. Afawi Z, Mandelstam S, Korczyn AD, et al. TBC1D24 mutation associated with focal epilepsy, cognitive impairment and a distinctive cerebro-cerebellar malformation. Epilepsy Res 2013;105:240244.

3. Falace A, Filipello F, La Padula V, et al. TBC1D24, an ARF6interacting protein, is mutated in familial infantile myoclonic epilepsy. Am J Hum Genet 2010;87:365-370.

4. Guven A, Tolun A. TBC1D24 truncating mutation resulting in severe neurodegeneration. J Med Genet 2013;50:199-202.
5. Muona M, Berkovic SF, Dibbens LM, et al. A recurrent de novo mutation in KCNC1 causes progressive myoclonus epilepsy. Nat Genet 2015;47:39-46.

6. Milh M, Falace A, Villeneuve N, et al. Novel compound heterozygous mutations in TBC1D24 cause familial malignant migrating partial seizures of infancy. Hum Mutat 2013;34:869-872.

7. Campeau PM, Kasperaviciute D, Lu JT, et al. The genetic basis of DOORS syndrome: an exome-sequencing study. Lancet Neurol 2014;13:44-58. 